To our knowledge, this is the first case where a polymer analogous aromatization reaction of a Diels-Alder ladder polymer can be brought about. The fact that polymer 1a has an extended area of $\pi$-conjugation, is stable toward air and shows a structural relation with 'unwrapped' fragments of fullerenes will stimulate various physicochemical and synthetic investigations.

Received 10 January; accepted 16 March 1994.

1. Schlüter, A.-D. Adv. Mater. 3, 282-291 (1991).

2. Kroto, H. W., Heath, J. R., O'Brien, S.C., Cure, R. F. \& Smalley, R. E. Nature $\mathbf{3 1 8}, \mathbf{1 6 2 - 1 6 3}$ (1985).

3. Krätschmer, W., Lamb, L. D., Fostiropoulos, K. \& Huffman, D. R. Nature 347, 354-358 (1990).

4. Schwoerer, M. Phys. Bull. 50, 52-55 (1994).

5. Burroughes, J. H. et al. Nature 347, 539-541(1990)

6. Braun, D. \& Heeger, A. J. appl. Phys. Lett. 68, 1982-1984 (1991)

7. Ballauff M. Angew. Chem int Edn engt. 28, 253-268 (1989)

7. Ballauff, M. Angew. Chem. int. Edn engl. 28, 253-268 (1989).

8. Feast, W. J. \& Edwards, J. H. Polymer 21, 595-596 (1980).

Wessling, R. A. in J. Polym. Sci., Polym. Symp. Vol. 72 (eds Mark. H. \& Overberger, G. C.) 55-58 (Wiley, New York, 1985).

10. Lenz, R. W., Han, C.-C., Stenger-Smith, J. \& Karasz, F. E. J. Polym. Sci., Polym. Chem.. 26, 3241-3249 (1988).

11. Stille, J. K., Noren, G. K. \& Green, L. J. Polym. Sci., Polym. Chem. 8, 2245-2254 (1970) 12. Diederich, F. \& Whetten, R. L. Acct Chem. Res. 25, 119-126 (1992)

ACKNOWLEDGEMENTS. We thank H.-H. Limbach and O. Klein for recording the CPMAS spectrum. This work was supported by the Deutsche Forschungsgemeinschaft and the Fonds der Chemischen Industrie.

\section{Growth of oriented molecular sieve crystals on organophosphonate films}

\section{S. Feng \& T. Bein*}

Department of Chemistry, Purdue University, West Lafayette, Indiana 47907, USA

THE successful construction of complex organic/inorganic biomimetic systems ${ }^{1-3}$ has demonstrated the great power of supramolecular pre-organization and templating in controlling crystal growth ${ }^{4}$. For instance, polar organic surfaces or surface-attached polar groups can induce the formation of thin films of iron oxide ${ }^{5}$. It would be of great interest, for the design of novel devices such as sensors or catalyst membranes ${ }^{6}$, to be able to control the growth on surfaces of porous crystals with oriented channels: such channels could, for example, control the access of molecules to the surface of a field-effect transistor in a sensor device. Films and membranes with non-oriented channels have been prepared by depositing or growing zeolite $^{7-12}$ crystals on metal or metal-oxide supports ${ }^{13-21}$; in one case $\mathrm{e}^{21}$, pre-grown crystals of an aluminophosphate zeolite were oriented by application of an electric field. Here we report the oriented growth of crystals of a zinco-phosphate zeolite on gold surfaces modified with metal phosphonate multilayer films. We attribute the high degree of orientation $(>90 \%)$ to a strong affinity between the phosphonic acid groups of the phosphate multilayer and the (111) faces of the growing crystals.

Phosphonic acid monolayers were formed on gold substrates (silicon wafers with a $2,000-\AA$ layer of gold on a $100-\AA$ chromium layer, pre-cleaned with air plasma) by means of sorption of 11-mercapto-1-undecanol (MUD) which was phosphorylated with $\mathrm{POCl}_{3} / 2,4,6$-collidine ${ }^{22-24}$. The asymmetric and symmetric $\mathrm{CH}_{2}$ stretching bands for the MUD monolayer (in the reflectionabsorption infrared (RAIR) spectrum at $85^{\circ}$ incidence) occur at 2,920 and $2,851 \mathrm{~cm}^{-1}$ (refs 23,$24 ; 2,919$ and $2,850 \mathrm{~cm}^{-1}$ ) both before and after phosphorylation. These frequencies indicate a well-ordered and tightly packed monolayer on the gold surface ${ }^{25}$. In an alternative synthesis, $\left[-\mathrm{S}\left(\mathrm{CH}_{2}\right)_{4} \mathrm{PO}_{3} \mathrm{H}_{2}\right]_{2}(\mathrm{DS})^{26}$ was deposited on gold. The phosphonic acid modified surfaces (layer thick-

* To whom correspondence should be addressed. ness from ellipsometry: 6-8 $\AA$ (DS); $16 \AA$ (MUD)) were immersed sequentially, at $25^{\circ} \mathrm{C}$, in $5.0 \mathrm{mM}$ zirconyl chloride and $1.25 \mathrm{mM} \mathrm{1,10-decanediylbis} \mathrm{(phosphonic} \mathrm{acid)} \mathrm{(DBPA)} \mathrm{aque-}$ ous solutions to give the zirconium phosphonate $(\mathrm{ZrP})$ trilayer (19 $\AA$ thick after the first three steps with $\left[-\mathrm{S}\left(\mathrm{CH}_{2}\right)_{4} \mathrm{PO}_{3} \mathrm{H}_{2}\right]_{2}$ in the first layer, and $26 \AA$ after three steps with MUD in the first layer). The mid-infrared region of the spectrum of a $\mathrm{ZrP}$ trilayer is dominated by the asymmetric phosphonate stretch, $v_{\mathrm{a}}\left(\mathrm{PO}_{3}^{2-}\right.$ ), at $1,077 \mathrm{~cm}^{-1}$ (ref. $22 ; 1,076 \mathrm{~cm}^{-1}$ ). The substrates were rinsed for $30 \mathrm{~min}$ with deionized water between all adsorption steps.

The zeolite $\mathrm{X}$ analogue $(\mathrm{Na}, \text { dabco })_{96}\left(\mathrm{ZnPO}_{4}\right)_{96}$. $192 \mathrm{H}_{2} \mathrm{O}^{27}(\mathrm{ZnP})$ was prepared from a clear solution containing $32 \mathrm{mmol} \mathrm{NaOH}, \quad 134 \mathrm{mmol}$ 1,4-diazabicyclo[2.2.2]octane (dabco) and $64 \mathrm{mmol} \mathrm{H}_{3} \mathrm{PO}_{4}$, in $75 \mathrm{ml}$ of water that was cooled to $7^{\circ} \mathrm{C}$. To this was added a pre-cooled solution of $48 \mathrm{mmol}$ $\mathrm{Zn}\left(\mathrm{NO}_{3}\right)_{2}$ in $10 \mathrm{ml}$ of water to give a gel that converts to a 'milk' on shaking. The 'milk' settles rapidly and the crystallization was completed after $5 \mathrm{~h}$ at $7^{\circ} \mathrm{C}$. For thin film depositions, the gold substrates (pre-coated with phosphonate films) were reacted with the above synthesis mixture after the 'milk' had just settled. The substrates were carefully placed face-down into the zincophosphate mixture for crystallization at $7^{\circ} \mathrm{C}$, for $5 \mathrm{~h}$, then washed with water.

The phosphonate multilayer films promote the nucleation of phosphate molecular sieves from the hydrothermal synthesis mixtures as depicted in Fig. 1. No zeolite crystals become attached to the fresh gold surface without the metal-phosphonate multilayer films. Scanning electron micrographs of the films show that single layers of zinco-phosphate crystals are produced (Fig. 2). The majority ( $>90 \%$ ) of the crystals have grown with their basal surfaces oriented parallel to one of the (111) planes of the zeolite structure. They have the same octahedral morphology as the bulk material, with the important difference that the base faces in contact with the substrate are truncated triangles. The more ordered MUD-based ZrP films promote more oriented

Attachment of zeolite nuclei to organophosphonate film

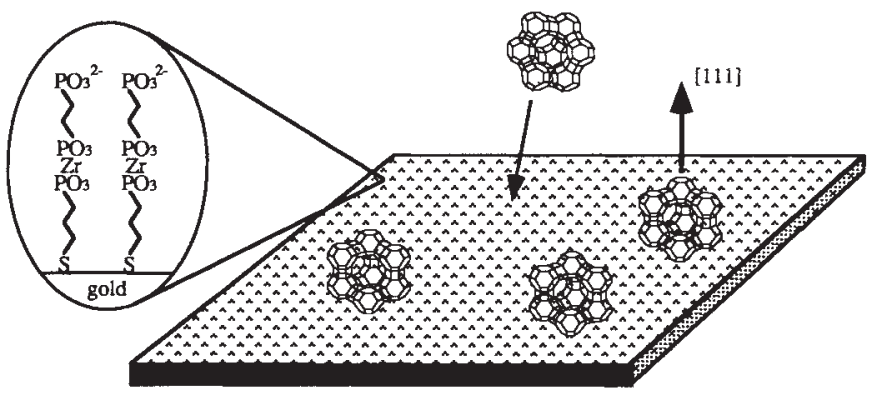

Crystal growth

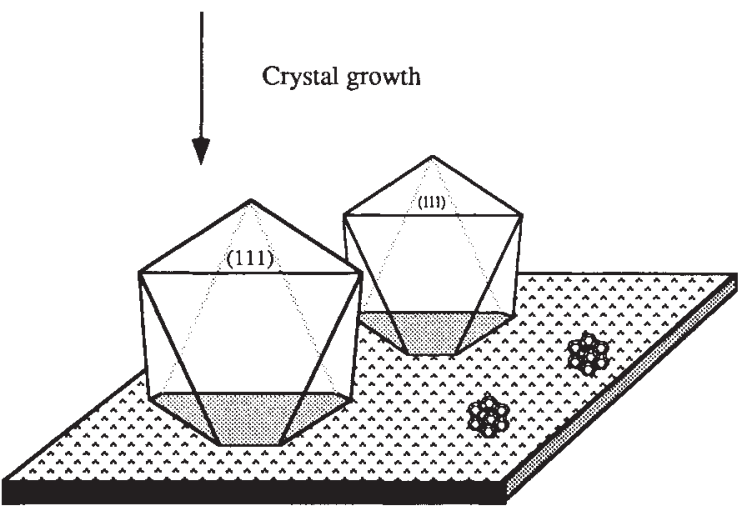

FIG. 1 Proposed reaction scheme for the growth of zinco-phosphate molecular sieves on organophosphonate films. 


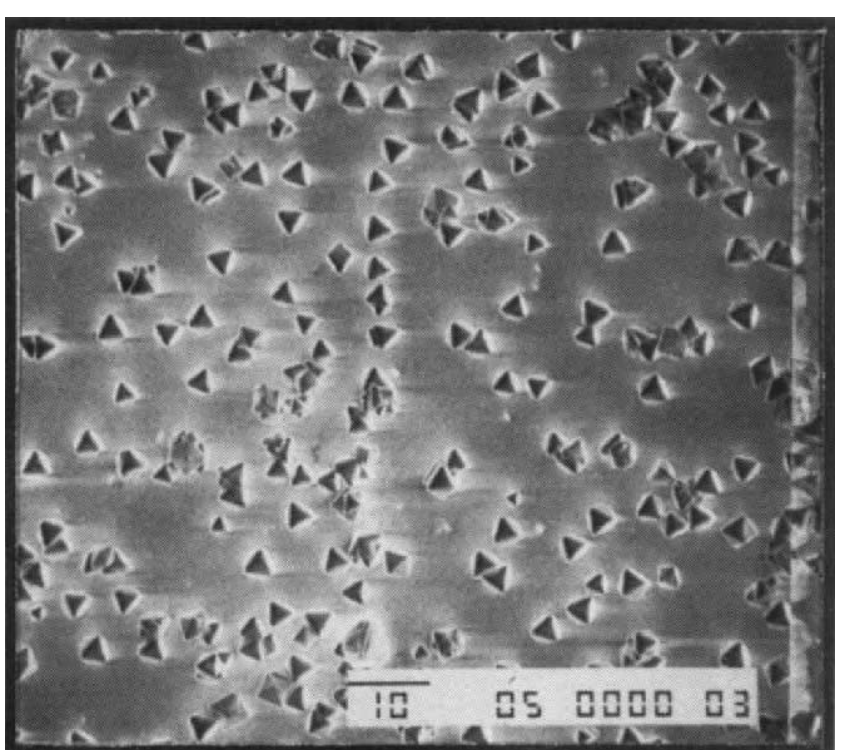

FIG. 2 Scanning electron micrograph of zinco-phosphate molecular sieves grown on organophosphonate-film-modified gold substrate (scale bar, $10 \mu \mathrm{m})$.

and homogeneous zinco-phosphate molecular sieve films compared to the $\left[-\mathrm{S}\left(\mathrm{CH}_{2}\right)_{4} \mathrm{PO}_{3} \mathrm{H}_{2}\right]_{2}$-based $\mathrm{ZrP}$ films.

The almost perfect orientation of the crystals is further supported by the high intensity of the (111) peak (ref. 27) in grazingangle $\left(1.5^{\circ}\right) \mathrm{X}$-ray diffraction patterns (Fig. $3 a$ ). The peak positions in the diffraction pattern of the film match perfectly with that of bulk zinco-phosphate molecular sieve phase as in Fig.

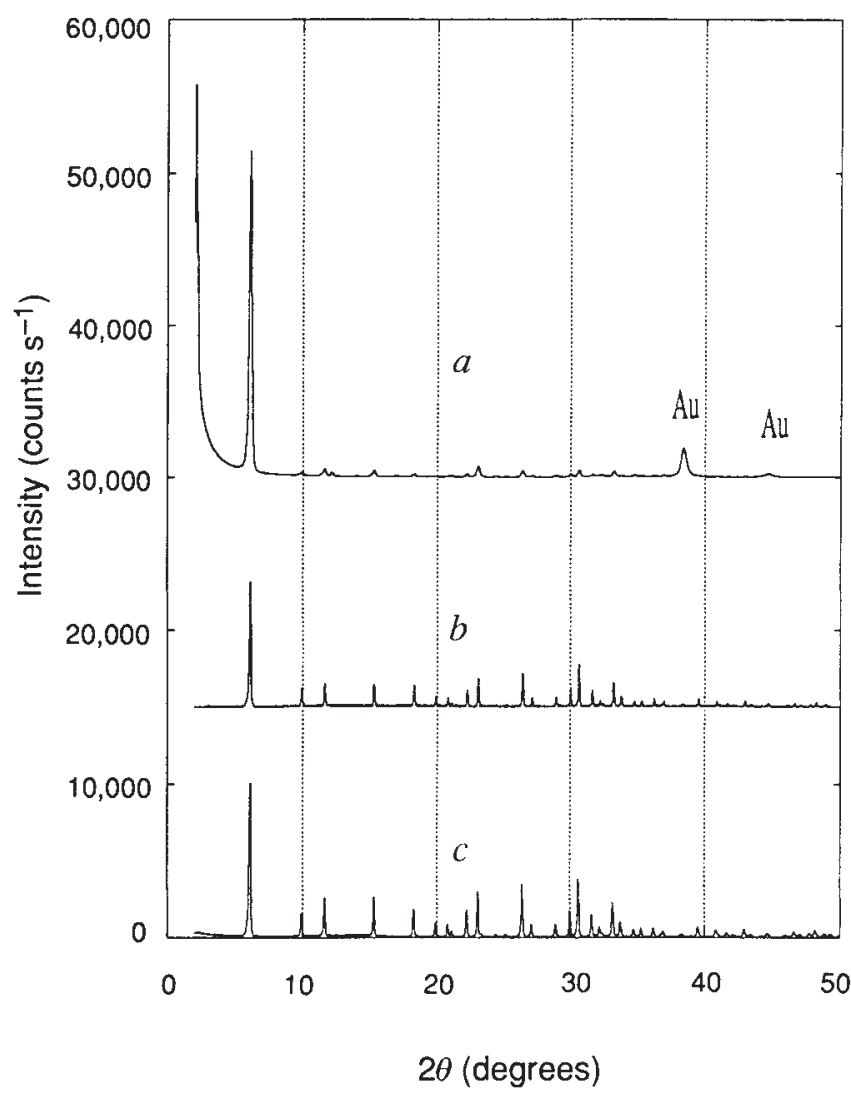

FIG. 3 X-ray diffraction patterns of a, zinco-phosphate molecular sieve film on organophosphonate films (offset), $b$, the molecular sieve crystals recovered from the gold substrate (offset, $2 x$ ) and $c$, bulk zincophosphate molecular sieve.
$3 c$. In addition, the molecular sieve crystals recovered from the gold substrate gave the same X-ray diffraction pattern and peak ratios as the bulk (Fig. $3 b$ ). The zinco-phosphate crystals are bonded strongly enough to the substrate to survive hours of sonication.

Significant crystal growth occurs only when at least the trilayer MUD(DS)-Zr-DBPA is present on the surface. We associate the absence of crystal growth on the $-\mathrm{S}\left(\mathrm{CH}_{2}\right)_{4} \mathrm{PO}_{3} \mathrm{H}_{2}$ monolayer with lack of order, and absence of a homogeneous surface of phosphate groups for favourable electrostatic interactions in this film, as indicated by RAIR spectra. The films obtained after adding zirconyl chloride show no crystal growth at all, suggesting a lack of electrostatic interactions. Finally, the more ordered trilayer MUD(DS)-Zr-DBPA film with phosphonate groups exposed on the outer surface provides an effective nucleation and growth substrate. The organic templating agents are also important to control the molecular sieve growth. No crystal growth occurs when tetramethyl ammonium hydroxide (TMA) instead of dabco is used as the template. This effect may be related to the dipositive charge on dabco and its resulting surface association in the synthesis.

What is the reason for the dramatic effect of the organic layers on the crystal growth? Quenching reactions were used to explore the association between the phosphonate surface and zeolite crystal faces. To the bulk zinco-phosphate crystallization mixture (with $57.6 \mathrm{mmol} \mathrm{H}_{3} \mathrm{PO}_{4}$ ) was added methylphosphonic acid (6.4 $\mathrm{mmol} \mathrm{H}_{2} \mathrm{PO}_{3} \mathrm{CH}_{3}$ ) after $30 \mathrm{~min}$ and after $1 \mathrm{~h}$, and the mixture was kept at $7^{\circ} \mathrm{C}$ for another $5 \mathrm{~h}$. If the phosphonic acid derivative attaches to the crystal surface, the tail group $\left(-\mathrm{CH}_{3}\right)$ could be expected to block further crystal growth. X-ray diffraction patterns and electron micrographs show that addition of the 'quenching agent' stops crystallization immediately. The results confirm that the phosphonic acid groups have a strong affinity to the growing (111) faces of the molecular sieve crystals.

To explore the porosity of the zinco-phosphate films, the occluded dabco molecules were exchanged with cations to avoid the conventional high temperature calcination treatment which is known to destroy the zinco-phosphate structure ${ }^{27}$. ZnP film was grown on a quartz crystal microbalance ${ }^{20,28}$ with gold electrodes, as described above, and treated with $0.5 \mathrm{M} \mathrm{NaCl}$ solution for $12 \mathrm{~h}$ (the removal of dabco in similar bulk experiments is fairly complete; the carbon content decreases from 24 to $2.4 \mathrm{wt} \%$ ). The film was then dehydrated in a stream of dry helium $\left(12 \mathrm{~h}\right.$ at $\left.20^{\circ} \mathrm{C}\right)$, and its water sorption isotherm was

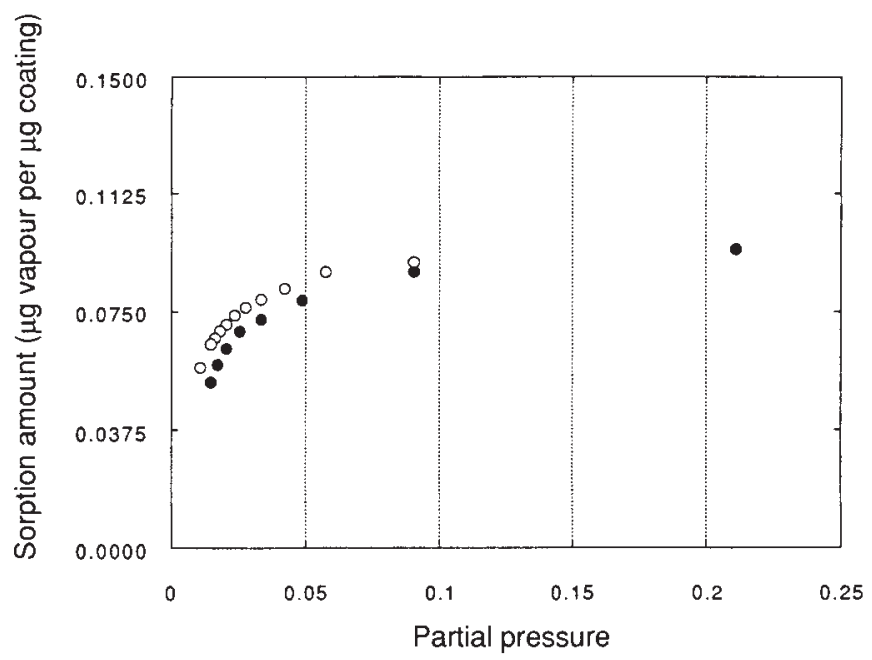

FIG. 4 Water sorption isotherm of zinco-phosphate crystals grown on the surface of a quartz crystal microbalance at $20^{\circ} \mathrm{C}$ (partial pressure is $P / P_{0}$, and $P_{0}=17.5$ torr). Vapour exposure was $\sim 12$ min per data point. The small offset of the desorption points shows that the film was close to equilibrium, even at this low temperature. 
measured in situ in a flow system (Fig. 4). The typical micropore sorption isotherm (here with saturation at a partial pressure $P / P_{0}$ of $\sim 0.09$ ) is apparent and confirms the presence of molecular sieve material in the film.

In conclusion, we have discovered strategies to grow oriented molecular sieve crystals on gold substrates. Zirconium phosphonate surfaces most probably interact with the growing inorganic zinco-phosphate crystals through electrostatic and geometric matching processes. The $\left[-\mathrm{PO}_{3} \mathrm{H}_{2}\right]$ surfaces are effective at stabilizing the $\{111\}$ faces of zinco-phosphate. It seems unlikely that individual $\mathrm{Zn}^{2+}$ and $\mathrm{PO}_{4}^{3-}$ ions can assemble the zeolite structure on the organic film. We propose that small

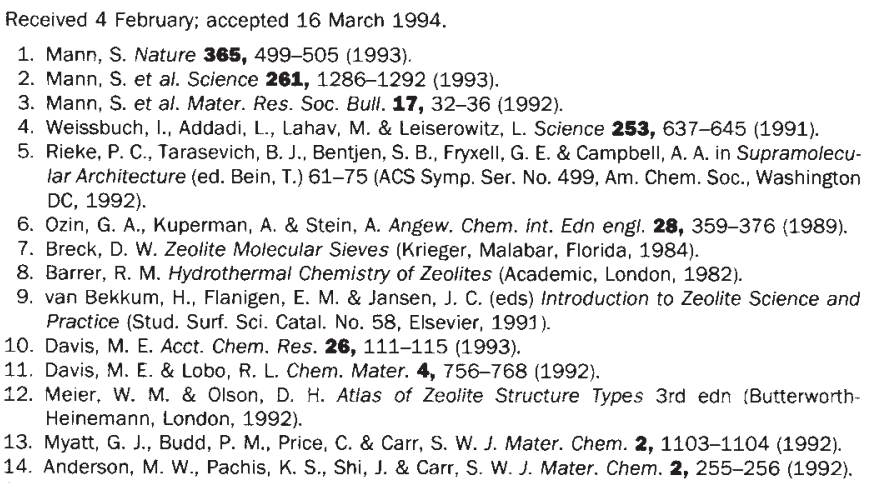

zinco-phosphate nuclei attach and orient themselves on the film, possibly assisted by preadsorption of $\mathrm{Zn}^{2+}$ or dabco species on the surface (Fig. 1).

To our knowledge, these systems are the first examples of oriented, surface-controlled growth of molecular sieve crystals. Further studies of the surface reactions involved here should increase our understanding of nucleation processes in molecular sieve synthesis, and additional organized systems should result. These materials could offer exciting applications, such as controlled access of molecules of pre-selected size to a sensor surface, or orientation of molecules for nonlinear optical applications.

16. Creasy, K. E. et al. in Mater. Res. Soc. Symp. Proc. Vol. 233 (eds Bedard, R. L. et al.) 157167 (Mater. Res. Soc., Pittsburgh, 1991).

17. Tsikoyiannis, J. G. \& Haag, W. O. Zeolites 12, 126-130 (1992).

18. Geus, E. R., Den Exter, M. J. \& van Bekkum, H. J. chem. Soc., Faraday Trans. 88, 3101 3109 (1992)

19. Bein, T., Brown, K., Frye, G. C. \& Brinker, C. J. J. Am. chem. Soc. 111, 7640-7641 (1989).

20. Yan, Y. \& Bein, T. J. phys. Chem. $96,9387-9393(1992)$.

21. Caro, J. et al. Adv. Mater. 4, 273-276 (1992)

22. Putvinski, T. M. et al. Langmuir 6, 1567-1571 (1990)

23. Katz, H. E. et al. Science 254, 1485-1487 (1991).

24. Frey, B. L., Hanken, D. G. \& Corn, R. M. Langmuir 9, 1815-1820 (1993)

25. Chidsey, C. E. D. \& Loiacono, D. N. Langmuir 6, 682-691 (1991).

26. Lee, H., Kepley, L. J., Hong, H. G., Akhter, S. \& Mallouk, T. E. J. phys. Chem. 92, $2597-$ 2601 (1988)

27. Gier, T. E. \& Stucky, G. D. Nature 349, 508-510 (1991)

28. Ward, M. D. \& Buttry, D. A. Science 249, 1000-1007 (1990).

ACKNOWLEDGEMENTS. This material is based on work supported by the US NSF and by the Purdue Research Foundation.

\section{Formation of amide bonds without a condensation agent and implications for origin of life}

\author{
M. Keller*, E. Blöchl*, G. Wächtershäusertł \\ \& K. O. Stetter*
}

* Lehrstuhl für Mikrobiologie, 93040 Regensburg, Germany $\dagger$ Tal 29, 830331 Munich, Germany

AMIDE bonds are of central importance for biochemistry; in the guise of peptide bonds, they form the backbone of proteins. The formation of amide bonds without the assistance of enzymes poses a major challenge for theories of the orgin of life. Enzyme-free formation of amide bonds between amino acids has been demonstrated in the presence of condensing agents such as cyanamide ${ }^{1-4}$. Here we report the formation of amide bonds in aqueous solution in the absence of any condensing agent. We find that the formation of pyrite $\left(\mathrm{FeS}_{2}\right)$ from $\mathrm{FeS}$ and $\mathrm{H}_{2} \mathrm{~S}$ can provide the driving force for reductive acetylation of amino acids with mercaptoacetic acid $\left(\mathrm{HSCH}_{2} \mathrm{COOH}\right)$. The redox energy of pyrite formation permits the activation of the carboxylic acid group, which is converted to a species that reacts readily with amines. This process provides support for the chemo-autotrophic theory ${ }^{5-8}$ for the origin of life, in which pyrite formation supplies the energy source for the first autocatalytic reproduction cycle.

The biosphere is divided between heterotrophic and autotrophic ways of life, raising the question of whether life began with one or the other. It is widely thought that life began heterotrophically in a prebiotic broth of nucleotides (the RNA world ${ }^{y, 10}$ ) and/or amino acids (for review see ref. 11). These theories suffer from the lack of a geochemically plausible energy source for driving the postulated condensation reactions to

$\ddagger$ To whom correspondence should be addressed. nucleic acids and/or polypeptides in an aqueous environment.

The theory of a chemo-autotrophic origin postulates as the first energy source for life the oxidative formation of pyrite from iron sulphide and hydrogen sulphide $\left(\mathrm{FeS}+\mathrm{HS}^{-} \rightarrow \mathrm{FeS}_{2}+\right.$ $\left.\mathrm{H}^{+}+2 \mathrm{e}^{-} ; \mathrm{E}^{0^{\prime}}=-620 \mathrm{mV}\right)^{5,6}$. The electrons are seen as being available for a reductive carbon-dioxide fixation cycle, specifically an archaic autocatalytic version of the reductive citric-acid cycle ${ }^{7}$. Within this theory $\alpha$-keto acids play a central role. It has been postulated that they can be reduced at the $\alpha$-position by the addition of hydrogen sulphide and subsequent desulphurization

\begin{tabular}{|c|c|c|c|c|}
\hline Amine & $\mathrm{HSCH}_{2} \mathrm{COOH}$ & $\mathrm{H}_{2} \mathrm{~S}$ & $N$-acetyl o & Ids $(\mu \mathrm{mol})$ \\
\hline$(100 \mu \mathrm{mol})$ & $(\mu \mathrm{mol})$ & $(\mu \mathrm{mol})$ & $2 d$ & $4 d$ \\
\hline Aniline & 50 & 2,000 & 0.55 & 0.9 \\
\hline Aniline & 50 & 0 & 0.25 & 0.4 \\
\hline o-Carboxy- & & & & \\
\hline aniline & 50 & 2,000 & 0.29 & 0.42 \\
\hline Tyrosine & 5,000 & 2,000 & 1.2 & 1.8 \\
\hline Tyrosine & 5,000 & 0 & 0.2 & 0.3 \\
\hline
\end{tabular}

All procedures were carried out under argon. The solutions were prepared from doubly distilled water through which $\mathrm{Ar}$ had been bubbled for $2 \mathrm{~h}$. Amorphous FeS was prepared in an anaerobic chamber by adding a solution of $\mathrm{Na}_{2} \mathrm{~S} \cdot 9 \mathrm{H}_{2} \mathrm{~S}$ to $0.6 \mathrm{M} \mathrm{FeSO}_{4}$, filtering the precipitate, washing it with $\mathrm{H}_{2} \mathrm{O}$ and drying it under $\mathrm{N}_{2}: \mathrm{H}_{2}=95: 5$. The $\mathrm{H}_{2} \mathrm{~S}$ was prepared by adding $50 \% \mathrm{H}_{2} \mathrm{SO}_{4}$ to $\mathrm{Na}_{2} \mathrm{~S} \cdot 9 \mathrm{H}_{2} \mathrm{O}$ in an evacuated serum bottle. Mercaptoacetic acid (Merck) was distilled under vacuum and immediately dissolved in water to a concentration of $5 \mathrm{mM}$. In the anaerobic chamber, serum bottles $(120 \mathrm{ml})$ were charged with $10 \mathrm{ml} \mathrm{H}_{2} \mathrm{O}$, $2 \mathrm{mM}$ FeS, $100 \mu \mathrm{M}$ of the amino compound and an amount of mercaptoacetic acid given in the Table, closed with a 'viton' diaphragm (Ochs), supplied with an Ar atmosphere (200 kPa) and subsequently charged with $\mathrm{H}_{2} \mathrm{~S}$ ( $2 \mathrm{mmol}$ ). The $\mathrm{pH}$ was adjusted to 4.5 . All incubations were carried out at $100^{\circ} \mathrm{C}$ in a rotary shaker (100 r.p.m.). The yield of the $N$-acetyl compound ( $\mu \mathrm{mol}$ ) was determined after 2 and 4 days by highperformance liquid chromatography (HPLC) under the conditions given in Fig. 1. It decreases with increasing pH (not shown). 